\title{
Experimental and theoretical evaluation of the stability of true MOF polymorphs explains their mechanochemical interconversions
}

\author{
Zamirbek Akimbekov, Athanassios D. Katsenis, GP Nagabhushana, Ghada Ayoub, Mihails Arhan- \\ gelskis, Andrew J. Morris, Tomislav Friščić* and Alexandra Navrotsky*
}

Peter A. Rock Thermochemistry Laboratory and NEAT ORU, University of California, Davis, One Shields Avenue, Davis, CA 95616 U.S.A.; Department of Chemistry, McGill University, 801 Sherbrooke St. W., Montreal, Canada H3A 0B8; Cavendish Laboratory, University of Cambridge, 19 J. J. Thomson Avenue, Cambridge CB30HE, UK.

\begin{abstract}
We provide the first combined experimental and theoretical evaluation of how differences in ligand structure and framework topology affect the relative stabilities of isocompositional (i.e. true polymorph) metal-organic frameworks (MOFs). We used solution calorimetry and periodic DFT calculations to analyze thermodynamics of two families of topologically-distinct polymorphs of zinc zeolitic imidazolate frameworks (ZIFs) based on 2-methyl- and 2-ethylimidazolate linkers, demonstrating a correlation between measured thermodynamic stability and density, and a pronounced effect of the ligand substituent on their stability. The results show that mechanochemical syntheses and transformations of ZIFs are consistent with Ostwald's rule of stages and proceed toward thermodynamically increasingly stable, more dense phases.
\end{abstract}

\section{Introduction}

Microporous materials, such as zeolites ${ }^{1-5}$ and metal-organic frameworks (MOFs) ${ }^{6-12}$ are of high technological importance in catalysis, ${ }^{13-16}$ gas storage ${ }^{17,18}$ and separation, ${ }^{19-23}$ and other applications. ${ }^{24}$ Whereas the uses of zeolites are well established, the first commercial applications of MOFs have just been announced. ${ }^{25}$ Zeolitic imidazolate frameworks (ZIFs, a family of metal azolate frameworks), ${ }^{26,27}$ composed of tetrahedrally-coordinated metal $(\mathrm{Zn}, \mathrm{Cd}, \mathrm{Co})^{28-30}$ centers interconnected by imidazolate linkers are a class of MOFs that inherit their structural and physicochemical features from both MOFs and zeolites, ${ }^{31-}$ ${ }^{33}$ and have been targeted for use in gas storage and separation, such as $\mathrm{CO}_{2}$ sequestration. ${ }^{34}$ As for zeolites, the basic design of ZIF structures allows for complex free energy landscapes and extensive polymorphism, ${ }^{35,36}$ with computational studies of ZIF energetics indicating that many new materials might in principle be accessible..$^{37,38}$ For example, density functional theory (DFT) total energy calculations suggest a rich landscape of polymorphs for the zinc(2-methylimidazolate $)_{2} \mathrm{Zn}(\mathbf{M e I m})_{2}$ framework. ${ }^{39}$ However, most synthetic studies give only the structure with open sodalite (SOD) topology, ZIF-8 (also known as MAF-4)..$^{31,40,41}$ This is surprising, as our earlier studies of heats of formation of MOFs suggest there should be little thermodynamic penalty for synthesizing diverse MOF true polymorphs, i.e. materials of the same chemical composition but different structure. The absence of a variety of such structures indicates kinetic or mechanistic limitations of conventional solutionbased syntheses, ${ }^{42-44}$ encouraging the exploration of alternative techniques, such as mechanochemistry ${ }^{45-47}$ or thermochemistry. ${ }^{47,48}$ Mechanochemistry was recently used to selectively access topologically different ZIFs, including previously unknown phases. ${ }^{28,49,50}$ Real-time in situ synchrotron X-ray diffraction studies revealed that such reactions proceed via multistep mechanisms, in which initially formed open frameworks convert into increasingly dense, isocompositional phases, i.e. true polymorphs. ${ }^{49,50}$ (a)

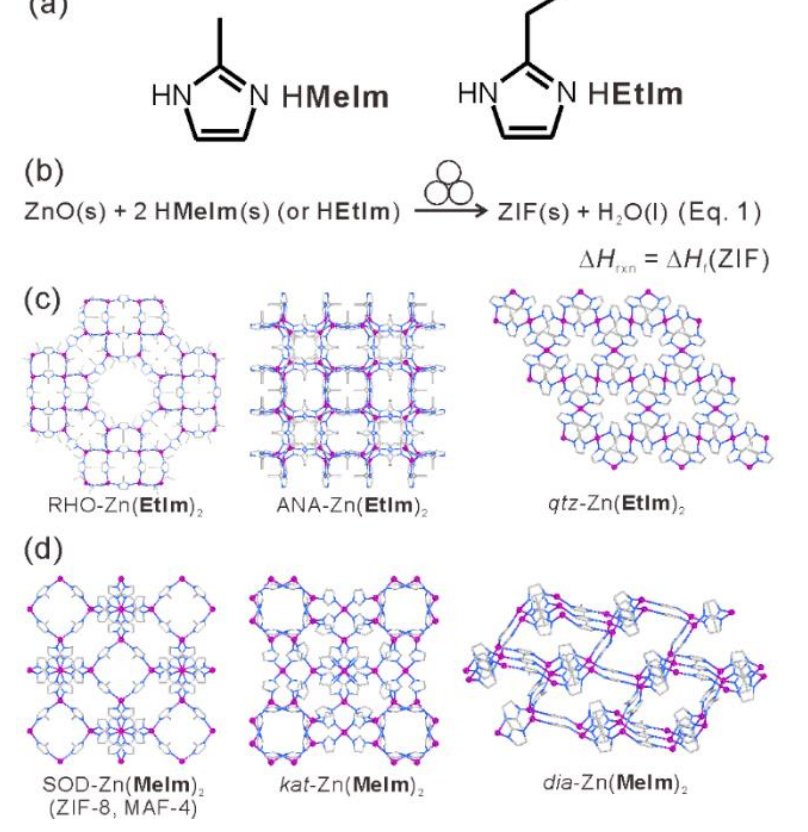

Figure 1. (a) 2-methylimidazole (HMeIm) and 2-ethylimidazole (HEtIm); (b) Formation reaction for studied thermodynamic changes. Crystal structures of polymorphs of: (c) $\mathrm{Zn}(\mathbf{E t I m})_{2}$ and (d) $\mathrm{Zn}(\mathbf{M e I m})_{2}$.

For example, it has been reported ${ }^{28,49}$ that $\mathrm{ZnO}$ and 2-ethylimidazole (HEtIm) (Figure 1a,b) under liquid-assisted grinding react to produce, sequentially, ZIFs with zeolite $\rho$ (RHO), ${ }^{51}$ analcime (ANA, also known as ZIF-14), and $\beta$-quartz ( $q t z$, well known in inorganic systems, e.g. $\mathrm{SiO}_{2}, \mathrm{GeO}_{2}, \mathrm{Al}_{0.5} \mathrm{P}_{0.5} \mathrm{O}_{2}$ ) topologies (Figure 1c). The reaction of 2-methylimidazole (HMeIm, Figure 1a,b) was shown ${ }^{50}$ to first yield ZIF-8, followed by katsenite (kat) and diamondoid (dia) topology frameworks (Figure 1d). It remains unclear if these mechanisms reflect Ostwald's rule of stages, i.e. formation of the thermodynamically preferred product via a series of increasingly stable phases. ${ }^{52}$ 
Nevertheless, mechanochemistry offers an excellent opportunity to access true polymorphs required to build a firm, rational understanding of structure-stability relationships in ZIFs.

We have now constructed quantitative experimental enthalpy profiles for two families of isocompositional ZIFs, based on HEtIm and HMeIm. ${ }^{53}$ By combining these results with modelling, we provide a unique experimental and theoretical study of structure-stability relationships of ZIF polymorphs, and explain the course of their mechanochemical transformations. Specifically, we used solution enthalpies in aqueous acid and a properly designed thermodynamic cycle (see Supplementary Materials) to calculate the enthalpies of transformation of ZIF polymorphs and enthalpy of their formation from $\mathrm{ZnO}$ and a corresponding ligand (Figure $1 \mathrm{~b}$ ). We show that the measured enthalpies of formation of a given ZIF are not affected by choice of solvothermal, mechanochemical or accelerated aging synthesis, and that the sequence of phases produced during ball milling indeed reflects a downhill progression through a dense energy landscape.

\section{Experimental Section}

All syntheses were performed following previously published mechanochemical or accelerated aging procedures. ${ }^{28,50,54,55}$ Mechanochemical syntheses were conducted in a stainless steel jar of $10 \mathrm{~mL}$ volume, using two $7 \mathrm{~mm}$ diameter (1.33 g each) stainless steel balls, and a Retsch MM400 mill operating at $30 \mathrm{~Hz}$. Accelerated aging was conducted in a Secador controlled humidity chamber at $100 \% \mathrm{RH}$, situated in an incubator set at $45^{\circ} \mathrm{C}$. MOF samples were washed with methanol and dried under vacuum.

\section{Solution calorimetry}

Enthalpies of solution of samples were measured with a CSC 4400 isothermal Microcalorimeter operating at $25^{\circ} \mathrm{C}$. A pellet ( $3-5 \mathrm{mg}$ ) of each chemical used in the thermodynamic cycle (Table S1) to determine enthalpies of formation of ZIF was prepared in an Ar filled glovebox, weighed using a Mettler microbalance, and dropped into $25.0 \mathrm{~g}$ of isothermally equilibrated 5 $\mathrm{M} \mathrm{HCl}$ aqueous solution inside a $50 \mathrm{~mL}$ Teflon cell in the calorimeter. After each experiment the cell was reassembled with fresh solvent. Mechanical stirring at approximately $1 / 2 \mathrm{~Hz}$ was applied to all experiments. The methodology is similar to that used earlier for other metal-organic frameworks. ${ }^{42}$ All reported errors are at the $95 \%$ confidence interval.

\section{Computational methods}

Crystal structures for the calculations were acquired from the Cambridge Structural Database (CSD). The following structures were used: dia-Zn(MeIm) $)_{2}$ (OFERUN01), kat$\mathrm{Zn}(\mathrm{MeIm})_{2} \quad$ (OFERUN08), $\quad$ SOD-Zn(MeIm) $)_{2} \quad$ (ZIF-8, OFERUN03), $q t z-\mathrm{Zn}(\mathbf{E t I m})_{2} \quad$ (EHETER), ANA-(EtIm) $)_{2}$ (MECWIB) and RHO-Zn(EtIm) $)_{2}(\mathrm{MECWOH})$. Any guest molecules present in the pores were deleted. The hypothetical $q t z-$, ANA- and RHO-Zn(EtIm $)_{2}$ structures were constructed from corresponding $\mathrm{Zn}(\mathbf{E t} \mathbf{I m})_{2}$ structures by replacing the terminal $-\mathrm{CH}_{3}$ group of the ethyl substituent in the 2-position of each imidazolate ligand with a hydrogen atom.

Periodic DFT calculations were performed with plane-wave DFT code CASTEP 16.1.1 $1^{55}$ The plane-wave cutoff was set to $750 \mathrm{eV}$ and norm-conserving pseudopotentials were used. The Brillouin zone was sampled with a $0.015 \AA^{-1} \mathrm{k}$-point spacing. Dispersion interactions were modelled with the aid of Grimme DFT-D $2^{57}$ dispersion correction. The optimization procedure involved full relaxation of unit cell parameters and atomic coordinates. The calculated lattice enthalpies were compared with the experimental results of the calorimetric measurements. Crystal structures were optimized subject to the symmetry constraints of their space groups. The I-centered cubic structures (for SOD-, ANA- and RHO-topologies) were transformed to corresponding primitive structures in order to reduce cell volume and, hence, computational cost. This transformation preserved all the symmetry operations of the original structures. For ANA-Zn(EtIm) $)_{2}$, symmetry of the structure had to be broken in order to adequately describe the disorder of ethyl groups. This structure was then optimized in the $P 1$ space group, with ethyl groups oriented so as to prevent any unrealistically short contacts arising from disorder.

\section{Results and Discussion}

The results (Table 1) show that the enthalpies of ZIF formation from $\mathrm{ZnO}$ and two imidazole equivalents $\left(\Delta H_{\mathrm{rxn}}\right)$ range from -20 to $-42 \mathrm{~kJ} \cdot(\mathrm{mol} \mathrm{Zn})^{-1}$ for all systems studied, confirming that the milling reaction is an exothermic process overall. A significant fraction of this exothermic character is due to changing the zinc coordination environment from an oxygen- to a nitrogen-based one, with the concomitant release of water, previously evaluated as $-46.7 \pm 1.0 \mathrm{~kJ} \cdot(\mathrm{mol})^{-1} \cdot{ }^{42}$ Subtracting this effect gives a new set of energies $\left(\Delta H_{\text {trans }}\right)$ for the transition from reactant phases to ZIFs. By excluding the enthalpic effects of water formation and changes in coordination environments, $\Delta H_{\text {trans }}$ serve as a measure of enthalpic contributions associated only with changes in supramolecular interactions and pore formation. The $\Delta H_{\text {trans }}$ values are all positive (Table 1), meaning that change in metal coordination from oxygen to nitrogen is the principal thermodynamic driving force for ZIF formation from $\mathrm{ZnO}$. As previous studies ${ }^{50,58}$ of mechanochemically prepared MOFs, including some of the herein studied ones, revealed that the particles are relatively large (in the range 100$200 \mathrm{~nm}$ ) nanoscale effects ${ }^{59}$ on herein measured energetics should be minimal.

The mechanochemical reaction of $\mathrm{ZnO}$ and HEtIm was reported $^{28,49}$ to yield the sequence of topologies $\mathrm{RHO} \rightarrow \mathrm{ANA} \rightarrow \mathrm{qtz}$. The $\Delta H_{\text {trans }}$ values (Table 1 ) show that the $\mathrm{RHO} \rightarrow$ ANA transformation involves an enthalpy change of $c a$. $-8 \mathrm{~kJ} \cdot(\mathrm{mol} \mathrm{Zn})^{-1}$ and is therefore (assuming that any $T \Delta S$ terms are small, especially at room temperature) thermodynamically driven (Figure 2). On further milling, ANA-Zn(Etlm) $)_{2}$ transforms into the final product, the dense $q t z-\mathrm{Zn}(\mathbf{E t} \mathbf{l m})_{2}(\mathrm{CCDC}$ EHETER) ${ }^{28,49}$ This transformation is again thermodynamically driven, with an enthalpy change of $-9.6 \mathrm{~kJ} \cdot(\mathrm{mol} \mathrm{Zn})^{-1}$ (Figure 2, Table 1).

Mechanochemical reaction of $\mathrm{ZnO}$ and HMeIm was reported to proceed via a series of structural transformations (Figure 2), including amorphization, ultimately leading to a dense-packed structure with dia-topology. The first phase in the reaction is ZIF-8, characterized by $\mathrm{MV}=240.99 \mathrm{~cm}^{3} \cdot(\mathrm{mol})^{-1} \quad(\mathrm{CCDC}$ OFERUN03) and herein measured $\Delta H_{\text {trans }}$ of $26.3 \pm 1.4 \mathrm{~kJ} \cdot(\mathrm{mol}$ $\mathrm{Zn})^{-1}$. Importantly, this $\Delta H_{\text {trans }}$ is similar to that previously measured for ZIF-8 made solvothermally $(27.1 \pm 1.9 \mathrm{~kJ} \cdot(\mathrm{mol} \mathrm{Zn})$ $\left.{ }^{1}\right) .{ }^{42} \mathrm{We}$ also conducted a calorimetric study on ZIF-8 prepared by the recently described accelerated aging technique, ${ }^{54,55}$ giving a $\Delta H_{\text {trans }}$ of $22.2 \pm 1.1 \mathrm{~kJ} \cdot(\mathrm{mol} \mathrm{Zn})^{-1}$. Overall, the $\Delta H_{\text {trans }}$ values measured for ZIF- 8 prepared solvothermally, mechanochemically and by accelerated aging are the same within experimental error (Table 1). 
Table 1. Physical Properties and Thermodynamic Data Used in and Derived from Solution Calorimetry.

\begin{tabular}{|c|c|c|c|c|c|c|}
\hline Compound & $\begin{array}{l}\mathrm{FD}^{\mathrm{a}, \mathrm{b}} \\
\left(\mathrm{T} / \mathrm{nm}^{3}\right)\end{array}$ & $\begin{array}{l}\mathrm{MV}^{\mathrm{b}} \\
\left(\mathrm{cm}^{3} \cdot(\mathrm{mol} \mathrm{Zn})^{-1}\right)\end{array}$ & $\begin{array}{l}\text { Void }{ }^{\mathrm{c}} \text { volume / } \\
\text { formula unit }\end{array}$ & $\begin{array}{l}\Delta \mathrm{H}_{\mathrm{s}} \\
\left(\mathrm{kJ} \cdot(\mathrm{mol})^{-1}\right)\end{array}$ & $\begin{array}{l}\Delta \mathrm{H}_{\mathrm{rxn}} \\
\left(\mathrm{kJ} \cdot(\mathrm{mol} \mathrm{M})^{-1}\right)\end{array}$ & $\begin{array}{l}\Delta \mathrm{H}_{\text {trans }} \\
\left(\mathrm{kJ} \cdot(\mathrm{mol} \mathrm{M})^{-1}\right)\end{array}$ \\
\hline $\mathrm{ZnO}$ & - & - & - & $-72.29 \pm 0.17$ & & \\
\hline HMeIm & - & - & - & $-43.08 \pm 0.21$ & & \\
\hline HEtIm & - & - & - & $-45.68 \pm 0.08$ & & \\
\hline $\mathrm{H}_{2} \mathrm{O}$ & - & - & - & $-0.5^{\mathrm{h}}$ & & \\
\hline $\mathrm{SOD}-\mathrm{Zn}(\mathbf{M e I m})_{2}{ }^{\mathrm{d}, \mathrm{f}}$ & 2.5 & 240.99 & 201.9 & $-137.50 \pm 0.83$ & $-20.45 \pm 0.94$ & $26.25 \pm 1.38$ \\
\hline $\mathrm{SOD}-\mathrm{Zn}(\mathbf{M e I m})_{2}, \mathrm{e}$ & 2.5 & 240.99 & 201.9 & $-133.50 \pm 0.20$ & $-24.45 \pm 0.50$ & $22.24 \pm 1.12$ \\
\hline$a-\mathrm{Zn}(\mathbf{M e I m})_{2}{ }^{\mathrm{g}}$ & - & - & - & $-130.63 \pm 0.48$ & $-27.32 \pm 0.66$ & $19.38 \pm 1.20$ \\
\hline$k a t-\mathrm{Zn}(\mathbf{M e I m})_{2}$ & 3.9 & 155.83 & 17.5 & $-129.20 \pm 0.42$ & $-28.75 \pm 0.62$ & $17.95 \pm 1.18$ \\
\hline $\operatorname{dia}-\mathrm{Zn}(\mathbf{M e I m})_{2}$ & 4.4 & 136.12 & 0 & $-127.86 \pm 1.08$ & $-31.09 \pm 1.17$ & $15.61 \pm 1.54$ \\
\hline RHO-Zn(EtIm $)_{2}$ & 1.9 & 313.67 & 289.8 & $-139.51 \pm 0.82$ & $-23.64 \pm 0.85$ & $23.06 \pm 1.31$ \\
\hline $\mathrm{ANA}-\mathrm{Zn}(\mathbf{E t I m})_{2}$ & 2.6 & 230.28 & 133.7 & $-131.52 \pm 1.24$ & $-31.63 \pm 1.26$ & $15.07 \pm 1.61$ \\
\hline$q t z-\mathrm{Zn}(\mathbf{E t I m})_{2}$ & 3.9 & 154.63 & 0 & $-121.90 \pm 0.24$ & $-41.25 \pm 0.33$ & $5.45 \pm 1.05$ \\
\hline
\end{tabular}

${ }^{\mathrm{a}}$ framework density (FD) is defined as the number of tetrahedral nodes (T) per unit volume; ${ }^{\mathrm{b}}$ molar volume (MV) and FD are calculated based on published crystal structures following DFT optimization; ${ }^{\mathrm{c}}$ void volume is calculated using a $1.2 \AA$ radius probe; ${ }^{\mathrm{d}} \mathrm{SOD}-\mathrm{Zn}(\mathrm{MeIm})_{2}$ prepared mechanochemically; ${ }^{\mathrm{e}} \mathrm{SOD}-\mathrm{Zn}(\mathbf{M e I m})_{2}$ prepared by accelerated aging; ${ }^{\mathrm{f}}$ value for solvothermally-prepared $\mathrm{SOD}-\mathrm{Zn}(\mathbf{M e I m})_{2}$ is $-138.36 \pm 0.57 \mathrm{~kJ}$ mol ${ }^{-1}{ }^{2}{ }^{-1}$ ${ }^{\mathrm{g}}$ amorphous $\mathrm{Zn}(\mathbf{M e I m})_{2}$; ${ }^{\mathrm{h}}$ calculated enthalpy of dilution of water in $5 \mathrm{M} \mathrm{HCl} ; \Delta H_{\mathrm{s}}$, enthalpy of solution in $5 \mathrm{M} \mathrm{HCl}$ at $298 \mathrm{~K}$; $\Delta \mathrm{H}_{\mathrm{rxn}}$, enthalpy of formation from $\mathrm{ZnO}$ and organic components (Figure 1); $\Delta H_{\text {trans, }}$, coordination-corrected enthalpy of formation reaction (see text).

Further milling of ZIF-8 leads to amorphous $a$-Zn(MeIm) followed by the sequential appearance of kat- and dia-topology phases (respective CCDC codes OFERUN08 and OFERUN01). Calorimetric evaluation of thermodynamic stability of the amorphous $a-\mathrm{Zn}(\mathbf{M e I m})_{2}$ gave $\Delta H_{\text {trans }}=19.4 \pm 1.2 \mathrm{~kJ} \cdot(\mathrm{mol} \mathrm{Zn})$ ${ }^{1}$, showing that amorphization of ZIF-8 is thermodynamically favored. Both kat-Zn(MeIm $)_{2}$ and dia-Zn(MeIm $)_{2}$ were found to be thermodynamically favored to ZIF-8 and its amorphous counterpart, with $\Delta H_{\text {trans }}$ values of $18.0 \pm 1.2$ and $15.6 \pm 1.5$ $\mathrm{kJ} \cdot(\mathrm{mol} \mathrm{Zn})^{-1}$, respectively. These results, together with our earlier evaluation of stability of structures based on unsubstituted imidazole, ${ }^{60}$ show that low density ZIFs are less stable than corresponding amorphous phases. A similar trend has also been observed in silica zeolites. ${ }^{43,61}$

The measured stability trends offer an explanation for differences in behavior of open $\mathrm{Zn}(\mathbf{M e I m})_{2}$ and $\mathrm{Zn}(\mathbf{E t I m})_{2}$ frameworks. The most commonly encountered $\mathrm{Zn}(\mathbf{M e I m})_{2}$ form in the literature is ZIF-8, with reports of $\mathrm{dia}^{-62}$ and kat-phases appearing in 2011 and 2015, respectively. ${ }^{50}$ In contrast to persistence of ZIF-8, the open RHO-Zn(EtIm) $)_{2}$ readily collapses into the close-packed qtz-phase upon heating, milling or in moist air. ${ }^{55}$ This difference in stability cannot be explained by $\Delta H_{\text {trans }}$ values of SOD-Zn(MeIm $)_{2}$ and $\mathrm{RHO}-\mathrm{Zn}(\mathbf{E t I m})_{2}$, as these are very similar (Table 1). This in itself is remarkable, as the molar volume for RHO-Zn(EtIm $)_{2}$ is significantly higher than that for SOD-Zn(MeIm $)_{2}$, indicating that the ethyl substituent is more efficient in stabilizing an open structure. An explanation for the difference in stabilities of ZIF-8 and RHO-Zn(EtIm $)_{2}$ might be in the stability of corresponding densest phases: whereas the $\Delta H_{\text {trans }}$ for $q t z-\mathrm{Zn}(\mathbf{E t I m})_{2}$ is $5.45 \pm 1.05 \mathrm{~kJ} \cdot(\mathrm{mol} \mathrm{Zn})^{-1}$, for dia$\mathrm{Zn}(\mathbf{M e I m})_{2}$ it is $15.6 \pm 1.5 \mathrm{~kJ} \cdot(\mathrm{mol} \mathrm{Zn})^{-1}$. Consequently, the measured driving forces for the collapse of ZIF-8 and RHO$\mathrm{Zn}(\mathbf{E t I m})_{2}$ are $10.6 \mathrm{~kJ} \cdot(\mathrm{mol} \mathrm{Zn})^{-1}$ and $17.6 \mathrm{~kJ} \cdot(\mathrm{mol} \mathrm{Zn})^{-1}$, respectively. In other words, the driving force for the collapse of RHO-Zn(EtIm $)_{2}$ is ca. $70 \%$ higher compared to that of ZIF-8 due to high stability of $q t z-\mathrm{Zn}(\mathbf{E t I m})_{2}$.
Comparing the differences in $\Delta H_{\text {trans }}$ to differences in molar volumes between $q t z-\mathrm{Zn}(\mathbf{E t I m})_{2}$ and dia-Zn(MeIm) $)_{2}(154.6$ and $136.1 \mathrm{~cm}^{3} \cdot(\mathrm{mol} \mathrm{Zn})^{-1}$, respectively) again reveals a stabilizing effect of the ethyl group. This stabilizing effect is also evident in comparing $\Delta H_{\text {trans }}$ of SOD- $\mathrm{Zn}(\mathbf{M e I m})_{2}$ and ANA$\mathrm{Zn}(\mathbf{E t I m})_{2}$ : despite similarity in molar volumes (240.99 $\mathrm{cm}^{3} \cdot(\mathrm{mol} \mathrm{Zn})^{-1}$ vs. $230.28 \mathrm{~cm}^{3} \cdot(\mathrm{mol} \mathrm{Zn})^{-1}$, respectively),

(a)
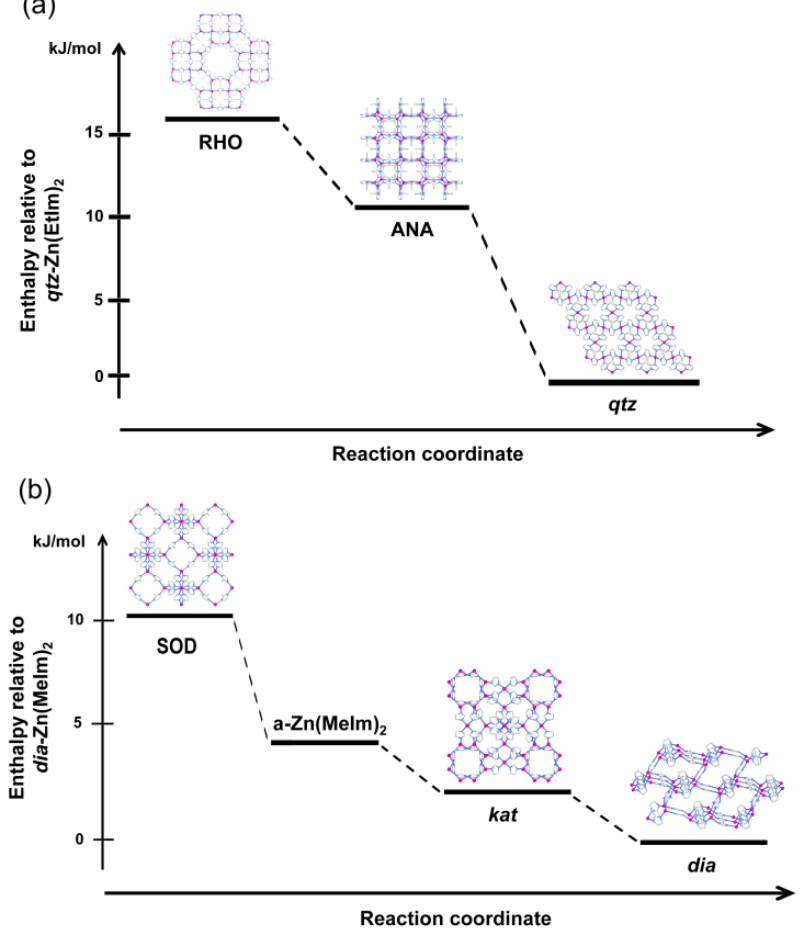

Figure 2. The sequence of previously observed ${ }^{8,25,26}$ mechanochemical polymorph transformations versus measured enthalpy of each phase, relative to the densest polymorph for: (a) $\mathrm{Zn}(\mathbf{E t I m})_{2}$ and (b) $\mathrm{Zn}(\mathbf{M e I m})_{2}$. In each case the transformation proceeds toward the more stable phase. 
ANA-Zn(EtIm) $)_{2}$ is ca. $11 \mathrm{~kJ} \cdot(\mathrm{mol} \mathrm{Zn})^{-1}$ more stable. The improvement in thermodynamic stability observed in 2-ethylimidazole-based ZIFs is also evident from a plot of measured $\Delta H_{\text {trans }}$ values vs. the framework density for HMeIm- and HEtImbased materials (see Supplementary Material).

Thus, by comparing the energy differences between true ZIF polymorphs versus ZIFs with different substituents, we can now begin separating the energetic effects of framework density and of substituents on the overall thermodynamic stability of ZIFs. It is interesting to note that the observed energy differences between ZIF polymorphs significantly exceed those between polymorphs of organic molecules, where lattice energy differences lie within $7.2 \mathrm{~kJ} \mathrm{~mol}^{-1}$ in $95 \%$ of cases. ${ }^{63}$

In order to better understand materials structural features responsible for observed energetic trends, ${ }^{64}$ we accompanied the calorimetric studies with CASTEP ${ }^{56}$ periodic DFT calculations (Table 2). In these calculations, the geometries of observed structures were fully optimized (atom coordinates and cell parameters) to yield total electronic energies. It is known that commonly used DFT functionals underestimate the energies of van der Waals interactions, ${ }^{65}$ potentially causing errors in calculated lattice energies and geometrical parameters of MOFs. ${ }^{50}$, 66-69 Correct description of dispersion forces was found to be crucial for modelling guest absorption in MOFs ${ }^{70-75}$ and for deriving their mechanical properties. ${ }^{76,77}$ While functionals tailored to reproduce van der Waals forces have been developed $^{78,79}$ and applied to ZIF systems, ${ }^{80}$ a more widely adopted approach for modelling them remains the semi-empirical dispersion correction (SEDC) in combination with one of the available general gradient approximation (GGA) or hybrid functionals. ${ }^{65,81}$ Dispersion-corrected DFT has been applied to ZIFs

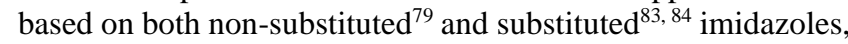
showing improved energy rankings compared to uncorrected DFT calculations. ${ }^{39}$ Nonetheless, polymorphic structures of $\mathrm{Zn}(\mathbf{M e I m})_{2}$ and $\mathrm{Zn}(\mathbf{E t I m})_{2}$ have not yet been comprehensively analyzed with dispersion-corrected DFT.

We used the $\mathrm{PBE}^{85}$ functional together with the Grimme D2 dispersion correction. ${ }^{57}$ Comparison of the calculated energies with measured enthalpies showed qualitative agreement and similar trends (Table 2). The agreement between calculated and experimentally measured energies of ZIF structures was assessed by means of weighted least squares (Figure 3 ). It is evident that calculations generally agree with measurements within experimental error. In quantitative terms, periodic DFT calculations appear to overestimate the relative energy gap between close-packed (dia and $q t z$ ) and open topologies, while the energy differences between pairs of open topologies (SOD and kat; RHO and ANA) were reproduced well. Importantly, the energy difference calculated here between SOD- and dia$\mathrm{Zn}(\mathbf{M e I m})_{2}$ is more realistic than that previously calculated ( $c a$. $1 \mathrm{~kJ} / \mathrm{mol}$ ) without dispersion correction. ${ }^{39}$ Theoretical modelling also confirmed the importance of the ethyl group for the stabilization of RHO-, ANA- and qtz-topologies. For this purpose, we generated hypothetical $\mathrm{Zn}(\mathbf{M e I m})_{2}$ structures with RHO-, ANA- and qtz-topology from corresponding Zn(EtIm $)_{2}$ structures by replacing the ethyl with a methyl group, followed by energy minimization. Calculations show that hypothetical ANA- and RHO-Zn(MeIm $)_{2}$ would be significantly higher in energy than any of the currently known $\mathrm{Zn}(\text { MeIm) })_{2}$ phases, and most likely are not observable (Table 2), further confirming the experimentally indicated efficiency of the ethyl substituent in stabilizing open structures.
Table 2. Calculated and measured crystal energies $\left(E_{\text {rel }}\right)$ for real and hypothetical $\mathrm{Zn}(\mathrm{EtIm})_{2}$ and $\mathrm{Zn}(\mathrm{MeIm})_{2}$ structures, in $\mathbf{k J} \cdot(\mathrm{mol})^{-1}$. All energies are given relative to the lowest energy polymorph for which $E_{\text {rel }}$ is set to zero.

\begin{tabular}{|c|c|c|c|}
\hline \multicolumn{2}{|l|}{ Framework } & $\begin{array}{l}E_{\text {rel }}\left(\mathrm{kJ} \cdot(\mathrm{mol})^{-1}\right) \\
(\text { measured) }\end{array}$ & $\begin{array}{l}E_{\mathrm{rel}}\left(\mathrm{kJ} \cdot(\mathrm{mol})^{-1}\right) \\
(\text { calculated) }\end{array}$ \\
\hline \multirow{6}{*}{$\mathrm{Zn}(\mathbf{M e I m})_{2}$} & dia & 0.0 & 0.0 \\
\hline & kat & 2.3 & 7.1 \\
\hline & $q t z^{\mathrm{a}}$ & - & 13.6 \\
\hline & SOD & 10.6 & 15.2 \\
\hline & $\mathrm{ANA}^{\mathrm{a}}$ & - & 25.8 \\
\hline & $\mathrm{RHO}^{\mathrm{a}}$ & - & 32.8 \\
\hline \multirow{3}{*}{$\operatorname{Zn}(\mathbf{E t I m})_{2}$} & $q t z$ & 0.0 & 0.0 \\
\hline & ANA & 9.6 & 19.6 \\
\hline & RHO & 17.6 & 27.5 \\
\hline
\end{tabular}

ahypothetical structures derived from RHO- (CCDC MECWOH), ANA$\left(\mathrm{CCDC}\right.$ MECWIB) and $q t z-\mathrm{Zn}(\mathbf{E t I m})_{2}(\mathrm{CCDC}$ EHETER).

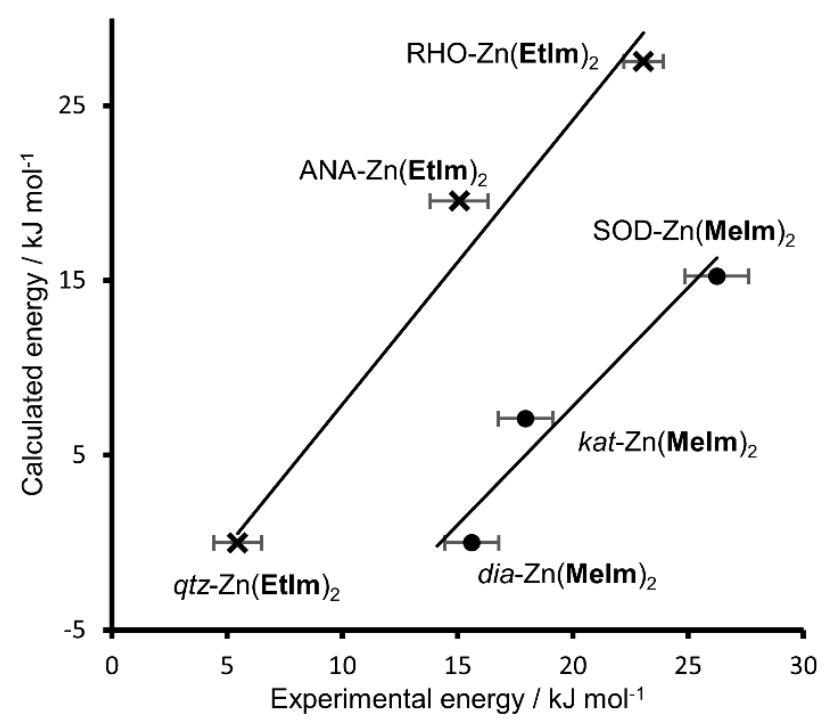

Figure 3. Comparison of the calculated and experimentally measured energies for real structures of $\mathrm{Zn}(\mathbf{E t I m})_{2}$ and $\mathrm{Zn}(\mathbf{M e I m})_{2}$. Calculated energies are given relative to the lowest energy polymorph for which energy is set to zero. Errors of the experimentally measured transition enthalpies, $\Delta H_{\text {trans, }}$ are shown by the error bars. The correlation between theoretical and experimental energies was assessed using weighted least squares method.

\section{Conclusions}

In conclusion, we provided the first combined calorimetric and theoretical modelling study of true polymorphs of MOFs. While providing an experimental evaluation of how the stability of ZIF polymorphs is affected by topological differences, this also led to the first experimental evidence that dispersion correction leads to a more realistic evaluation of their thermodynamic stability. Evaluating the thermodynamic stability of ZIF polymorphs led us to rationalize their previously observed mechanochemical transformations, showing that these follow Ostwald's rule of stages. Comparison of thermodynamic stabilities of ZIFs to their molecular volumes revealed the ability of ethyl groups to stabilize the frameworks more effectively than methyl 
substituents. By providing an experimental evaluation of theoretical modelling, and by demonstrating the ability to discern substituent effects on framework stability, this study advances the development of strategies to control and improve MOF stability. We are now continuing our work on other sets of MOF polymorphs.

\section{ASSOCIATED CONTENT}

\section{Supporting Information}

Further details of calorimetric experiments and characterization data for all investigated materials, as well as DFT-optimized structures for all herein explored real and hypothetical materials in CIF format. This material is available free of charge via the Internet at http://pubs.acs.org. Additional data related to this publication is available from the University of Cambridge data repository: https://doi.org/10.17863/CAM.8553.

\section{AUTHOR INFORMATION}

\section{Corresponding Author}

Alexandra Navrotsky, Peter A. Rock Thermochemistry Laboratory and NEAT ORU, University of California, Davis, One Shields Avenue, Davis, CA 95616 U.S.A. E-mail: anavrotsky@ucdavis.edu. Tomislav Friščić, Department of Chemistry, McGill University, 801 Sherbrooke St. W. H3A0B8 Montreal, Canada. E-mail: tomislav.friscic@mcgill.ca.

\section{Author Contributions}

The manuscript was written through contributions of all authors and all authors have given approval to the final version of the manuscript. All authors participated in the preparation of manuscript and data analysis.

\section{Notes}

The authors declare no competing financial interests.

\section{ACKNOWLEDGMENT}

Support for calorimetry was provided by the U.S. Department of Energy, Grant DE-SC0016573. We acknowledge the financial support of the NSERC Strategic Grant STPGP 463405-14.A.D.K. acknowledges support by the FRQNT Post-doctoral Scholarship. We are grateful for computational support from the UK national high performance computing service, ARCHER, for which access was obtained via the UKCP consortium and funded by EPSRC grant ref EP/K013564/1

\section{REFERENCES}

(1) Cheetham, A. K.; Férey, G.; Loiseau, T. Angew. Chem. Int. Ed. 1999, 38, 3268.

(2) Primo, A.; Garcia, H. Chem. Soc. Rev. 2014, 43, 7548.

(3) Li, Y.; Yu, J. Chem. Rev. 2014, 114, 7268.

(4) Roth, W. J.; Nachtigall, P.; Morris, R. E.; Čejka, J. Chem. Rev. 2014, 114, 4807.

(5) Cychosz, K. A.; Guillet-Nicolas, R.; García-Martínez, J.; Thommes, M. Chem. Soc. Rev. 2017, 46, 389.

(6) Eddaoudi, M.; Moler, D. B.; Li, H.; Chen, B.; Reineke, T. M.; O'Keeffe, M.; Yaghi, O. M. Acc. Chem. Res. 2001, 34, 319.

(7) Farha, O. K.; Hupp, J. T. Acc. Chem. Res. 2010, 43, 1166.

(8) Fracaroli, A. M.; Siman, P.; Nagib, D. A.; Suzuki, M.; Furukawa, H.; Toste, F. D.; Yaghi, O. M. J. Am. Chem. Soc. 2016, 138, 8352.

(9) Yaghi, O. M. J. Am. Chem. Soc. 2016, 138, 15507.

(10) Cui, Y.; Li, B.; He, H.; Zhou, W.; Chen, B.; Qian, G. Acc. Chem. Res. 2016, 49, 483.

(11) Zhang, Z.; Zaworotko, M. J. Chem. Soc. Rev. 2014, 43, 5444.
(12) Eddaoudi, M.; Sava, D. F.; Eubank, J. F.; Adil, K.; Guillerm, V. Chem. Soc. Rev. 2015, 44, 228.

(13) Roberts, J. M.; Fini, B. M.; Sarjeant, A. A.; Farha, O. K.; Hupp, J. T.; Scheidt, K. A. J. Am. Chem. Soc. 2012, 134, 3334.

(14) Deria, P.; Gómez-Gualdrón, D. A.; Hod, I.; Snurr, R. Q.; Hupp, J. T.; Farha, O. K. J. Am. Chem. Soc. 2016, 138, 14449.

(15) Lee, J. Y.; Roberts, J. M.; Farha, O. K.; Sarjeant, A. A.; Scheidt, K. A.; Hupp, J. T. Inorg. Chem. 2009, 48, 9971.

(16) Spivey, J. J.; Hutchings, G. Chem. Soc. Rev. 2014, 43, 792.

(17) Sung Cho, H.; Deng, H.; Miyasaka, K.; Dong, Z.; Cho, M.; Neimark, A. V; Ku Kang, J.; Yaghi, O. M.; Terasaki, O. Nature 2015 , $527,503$.

(18) Jiang, J.; Furukawa, H.; Zhang, Y.-B.; Yaghi, O. M. J. Am. Chem. Soc. 2016, 138, 10244.

(19) Xue, D.-X.; Cairns, A. J.; Belmabkhout, Y.; Wojtas, L.; Liu, Y.; Alkordi, M. H.; Eddaoudi, M. J. Am. Chem. Soc. 2013, 135, 7660.

(20) Duan, J.; Jin, W.; Kitagawa, S. Coord. Chem. Rev. 2017, 332, 48. (21) Bloch, E. D.; Queen, W. L.; Krishna, R.; Zadrozny, J. M.; Brown, C. M.; Long, J. R. Science 2012, 335, 1606.

(22) Herm, Z. R.; Wiers, B. M.; Mason, J. A.; van Baten, J. M.; Hudson, M. R.; Zajdel, P.; Brown, C. M.; Masciocchi, N.; Krishna, R.; Long, J. R. Science 2013, 340, 960.

(23) Kishida, K.; Okumura, Y.; Watanabe, Y.; Mukoyoshi, M.; Bracco, S.; Comotti, A.; Sozzani, P.; Horike, S.; Kitagawa, S. Angew. Chem. Int. Ed. 2016, 55, 13784.

(24) Gole, B.; Bar, A. K.; Mukherjee, P. S. Chem. Commun. 2011, 47, 12137.

(25) Faust, T. Nat. Chem. 2016, 8, 990.

(26) Tian, Y.-Q.; Cai, C.-X.; Ren, X.-M.; Duan, C.-Y.; Xu, Y.; Gao, S.; You, X.-Z. Chem. Eur. J. 2003, 9, 5673.

(27) Zhang, J.-P.; Zhang, Y.; Lin, J.; Chen, X. Chem. Rev. 2012, 112, 1001.

(28) Beldon, P. J.; Fábián, L.; Stein, R. S.; Thirumurugan, A.; Cheetham, A. K.; Friščić, T. Angew. Chem. Int. Ed. 2010, 49, 9640.

(29) Karagiaridi, O.; Bury, W.; Sarjeant, A. A.; Stern, C. L.; Farha, O. K.; Hupp, J. T. Chem. Sci. 2012, 3, 3256.

(30) Biswal, B. P.; Panda, T.; Banerjee, R. Chem. Commun. 2012, 48, 11868.

(31) Park, K. S.; Ni, Z.; Cote, A. P.; Choi, J. Y.; Huang, R.; UribeRomo, F. J.; Chae, H. K.; O'Keeffe, M.; Yaghi, O. M. Proc. Natl. Acad. Sci. 2006, 103, 10186.

(32) Wang, B.; Côté, A. P.; Furukawa, H.; O’Keeffe, M.; Yaghi, O. M. Nature 2008, 453, 207.

(33) Zhang, C.; Koros, W. J. J. Phys. Chem. Lett. 2015, 6, 3841.

(34) Phan, A.; Doonan, C. J.; Uribe-Romo, F. J.; Knobler, C. B.; O'Keeffe, M.; Yaghi, O. M. Acc. Chem. Res. 2010, 43, 58.

(35) Schweinefuß, M. E.; Springer, S.; Baburin, I. A.; Hikov, T.; Huber, K.; Leoni, S.; Wiebcke, M. Dalt. Trans. 2014, 43, 3528.

(36) Shi, Q.; Xu, W.-J.; Huang, R.-K.; Zhang, W.-X.; Li, Y.; Wang, P.; Shi, F.-N.; Li, L.; Li, J.; Dong, J. J. Am. Chem. Soc. 2016, 138, 16232. (37) Lewis, D. W.; Ruiz-Salvador, A. R.; Gomez, A.; RodriguezAlbelo, L. M.; Coudert, F.-X.; Slater, B.; Cheetham, A. K.; MellotDraznieks, C. CrystEngComm 2009, 11, 2272.

(38) Baburin, I. A.; Leoni, S.; Seifert, G. J. Phys. Chem. B 2008, 112, 9437.

(39) Baburin, I. A.; Leoni, S. J. Mater. Chem. 2012, 22, 10152.

(40) Huang, X. C.; Lin, Y. Y.; Zhang, J. P.; Chen, X. M. Angew. Chem. Int. Ed. 2006, 45, 1557.

(41) Venna, S. R.; Jasinski, J. B.; Carreon, M. A. J. Am. Chem. Soc. 2010, 132, 18030 .

(42) Hughes, J. T.; Bennett, T. D.; Cheetham, A. K.; Navrotsky, A. J. Am. Chem. Soc. 2013, 135, 598.

(43) Akimbekov, Z.; Navrotsky, A. ChemPhysChem 2016, 17, 468.

(44) Akimbekov, Z.; Wu, D.; Brozek, C. K.; Dincă, M.; Navrotsky, A. Phys. Chem. Chem. Phys. 2016, 18, 1158.

(45) James, S. L.; Adams, C. J.; Bolm, C.; Braga, D.; Collier, P.; Friščić, T.; Grepioni, F.; Harris, K. D. M.; Hyett, G.; Jones, W.; Krebs, A.; Mack, J.; Maini, L.; Orpen, A. G.; Parkin, I. P.; Shearouse, W. C.; Steed, J. W.; Waddell, D. C. Chem. Soc. Rev. 2012, 41, 413.

(46) Tanaka, S.; Kida, K.; Nagaoka, T.; Ota, T.; Miyake, Y. Chem. Commun 2013, 49, 7884. 
(47) Mottillo, C.; Friščić, T. Molecules 2017, 22, 144

(48) Lin, J.; Lin, R.; Cheng, X.; Zhang, J.; Chen, X. Chem. Commun 2011, 47, 9185.

(49) Friščić, T.; Halasz, I.; Beldon, P. J.; Belenguer, A. M.; Adams, F.; Kimber, S. A. J.; Honkimäki, V.; Dinnebier, R. E. Nat. Chem. 2013, 5, 66.

(50) Katsenis, A. D.; Puškarić, A.; Štrukil, V.; Mottillo, C.; Julien, P. A.; Užarević, K.; Pham, M.-H.; Do, T.-O.; Kimber, S. A. J.; Lazić, P.; Magdysyuk, O.; Dinnebier, R. E.; Halasz, I.; Friščić, T. Nat. Commun. 2015, 6, 6662 .

(51) He, C.-T.; Jiang, L.; Ye, Z.-M.; Krishna, R.; Zhong, Z.-S.; Liao, P.-Q.; Xu, J.; Ouyang, G.; Zhang, J.-P.; Chen, X.-M. J. Am. Chem. Soc. 2015, $137,7217$.

(52) Burley, J. C.; Duer, M. J.; Stein, R. S.; Vrcelj, R. M. Eur. J. Pharm. Sci. 2007, 31, 271.

(53) Chen, R.; Yao, J.; Gu, Q.; Smeets, S.; Baerlocher, C.; Gu, H.; Zhu, D.; Morris, W.; Yaghi, O. M.; Wang, H. Chem. Commun. 2013, 49, 9500 .

(54) Cliffe, M. J.; Mottillo, C.; Stein, R. S.; Bučar, D.-K.; Friščić, T. Chem. Sci. 2012, 3, 2495.

(55) Mottillo, C.; Lu, Y.; Pham, M.-H.; Cliffe, M. J.; Do, T.-O.; Friščić, T. Green Chem. 2013, 15, 2121

(56) Clark, S. J.; Segall, M. D.; Pickard, C. J.; Hasnip, P. J.; Probert, M. I. J.; Refson, K.; Payne, M. C. Zeitschrift für Krist. - Cryst. Mater. 2005, 220, 567.

(57) Grimme, S. J. Comput. Chem. 2006, 27, 1787

(58) Friščić, T.; Fábián, L. CrystEngComm 2009, 11, 743.

(59) Belenguer, A. M.; Lampronti, G. I.; Cruz-Cabeza, A. J.; Hunter, C.A.; Sanders, J.K.M. Chem. Sci. 2016, 7, 6617.

(60) Bennett, T. D.; Keen, D. A.; Tan, J.-C.; Barney, E. R.; Goodwin, A. L.; Cheetham, A. K. Angew. Chem. Int. Ed. 2011, 50, 3067.

(61) Navrotsky, A.; Trofymluk, O.; Levchenko, A. A. Chem. Rev. 2009, 109, 3885

(62) Shi, Q.; Chen, Z.; Song, Z.; Li, J.; Dong, J. Angew. Chem. Int. Ed. 2011, 50, 672 .

(63) Nyman, J.; Day, G. M. CrystEng Comm 2015, 17, 5154.

(64) Arhangelskis, M.; Eddleston, M. D.; Reid, D. G.; Day, G. M.; Bučar, D.-K.; Morris, A. J.; Jones, W. Chem. Eur. J. 2016, 22, 10065. (65) Marom, N.; Tkatchenko, A.; Rossi, M.; Gobre, V. V.; Hod, O.; Scheffler, M.; Kronik, L. J. Chem. Theory Comput. 2011, 7, 3944.
(66) Walker, A. M.; Civalleri, B.; Slater, B.; Mellot-Draznieks, C.; Corà, F.; Zicovich-Wilson, C. M.; Román-Pérez, G.; Soler, J. M.; Gale, J. D. Angew. Chem. Int. Ed. 2010, 49, 7501.

(67) Evans, J. D.; Fraux, G.; Gaillac, R.; Kohen, D.; Trousselet, F.; Vanson, J.-M.; Coudert, F.-X. Chem. Mater. 2017, 29, 199.

(68) Zasada, F.; Piskorz, W.; Gryboś, J.; Sojka, Z. J. Phys. Chem. C 2014, 118,8971

(69) Salih, Z. I.; Guo, Y.-J.; Zheng, J.-J.; Zhao, X. Comput. Theor. Chem. 2015, 1058, 28.

(70) Sillar, K.; Hofmann, A.; Sauer, J. J. Am. Chem. Soc. 2009, 131, 4143 .

(71) Grajciar, L.; Bludský, O.; Nachtigall, P. J. Phys. Chem. Lett. 2010, 1,3354 .

(72) Sillar, K.; Sauer, J. J. Am. Chem. Soc. 2012, 134, 18354.

(73) Kulkarni, A. R.; Sholl, D. S. Langmuir 2015, 31, 8453.

(74) Parkes, M. V.; Sava Gallis, D. F.; Greathouse, J. A.; Nenoff, T. M. J. Phys. Chem. C 2015, 119, 6556.

(75) Li, Y.; Wang, X.; Xu, D.; Chung, J. D.; Kaviany, M.; Huang, B. J. Phys. Chem. C 2015, 119, 13021.

(76) Haigis, V.; Belkhodja, Y.; Coudert, F.-X.; Vuilleumier, R.; Boutin, A. J. Chem. Phys. 2014, 141, 64703.

(77) Tan, J.-C.; Civalleri, B.; Erba, A.; Albanese, E. CrystEngComm 2015, 17, 375 .

(78) Dion, M.; Rydberg, H.; Schröder, E.; Langreth, D. C.; Lundqvist, B. I. Phys. Rev. Lett. 2004, 92, 246401.

(79) Langreth, D. C.; Dion, M.; Rydberg, H.; Schröder, E.; Hyldgaard, P.; Lundqvist, B. I. Int. J. Quantum Chem. 2005, 101, 599.

(80) Springer, S.; Baburin, I. A.; Heinemeyer, T.; Schiffmann, J. G.; van Wüllen, L.; Leoni, S.; Wiebcke, M. CrystEngComm 2016, 18, 2477

(81) Moellmann, J.; Grimme, S. J. Phys. Chem. C 2014, 118, 7615.

(82) Galvelis, R.; Slater, B.; Cheetham, A. K.; Mellot-Draznieks, C. CrystEngComm 2012, 14, 374.

(83) Galvelis, R.; Slater, B.; Chaudret, R.; Creton, B.; Nieto-Draghi, C.; Mellot-Draznieks, C. CrystEngComm 2013, 15, 9603.

(84) Mellot-Draznieks, C.; Kerkeni, B. Mol. Simul. 2014, 40, 25.

(85) Perdew, J. P.; Burke, K.; Ernzerhof, M. Phys. Rev. Lett. 1996, 77, 3865 . 
Authors are required to submit a graphic entry for the Table of Contents (TOC) that, in conjunction with the manuscript title, should give the reader a representative idea of one of the following: A key structure, reaction, equation, concept, or theorem, etc., that is discussed in the manuscript. Consult the journal's Instructions for Authors for TOC graphic specifications.
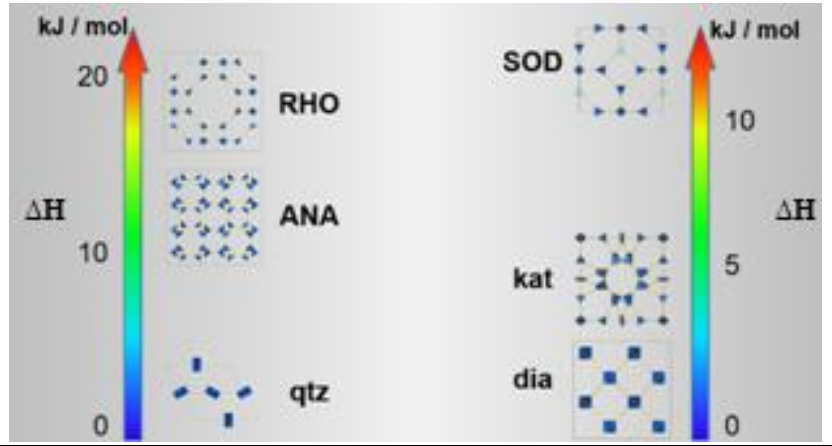